\title{
A Conversation Between Joseph Osborne and Thomas Hope
}

\author{
Joseph R. Osborne ${ }^{1}$ and Thomas A. Hope ${ }^{2}$ \\ ${ }^{I}$ Weill Cornell Medicine, New York, New York; and ${ }^{2}$ University of California, San Francisco, San Francisco, California
}

$\mathbf{J}$ oseph R. Osborne, MD, PhD, was interviewed by Thomas Hope, MD, an associate professor and director of molecular therapy for the Molecular Imaging and Therapeutics Clinical Section in the Department of Radiology and Biomedical Imaging at the University of California, San Francisco. Osborne is a professor of radiology and chief of molecular imaging and therapeutics at Weill Cornell Medicine and an attending physician at NewYorkPresbyterian/Weill Cornell Medicine (both in New York, NY). He earned his MD at Columbia College of Physicians and Surgeons (New York, NY) and his $\mathrm{PhD}$ in biochemistry at Columbia's Graduate School of Arts and Sciences. After an internship at the Washington Hospital Center (DC), Osborne completed a residency in diagnostic radiology at Columbia Presbyterian Hospital, followed by fellowship training in nuclear medicine. He also completed postdoctoral training at Memorial Sloan Kettering Cancer Center (New York, NY).

Osborne is the director of the MI4 (Molecular Imaging Innovations Institute for Inclusion; https://radiology.weill.cornell. edu/research/mi3) at Weill Cornell Medicine, where his goal as a physician and scientist is to promote practical, value-added molecular imaging closely aligned with precision medicine. He is currently the principal investigator on a National Institutes of Health academic-industrial partnership R01 grant for "A New Technique to Make ${ }^{68}$ Ga-Labeled Pharmaceuticals Widely Available for Clinical Use" and a recipient of the Dean's Health Disparity Research Award for the Prostate Cancer Health Impact Program. He is the Investigator Development Core director at the Weill Cornell Center for Health Equity (https://centerforhealthequity.cornell.edu/). He has served as program director of the nuclear medicine residency program at New York-Presbyterian/ Weill Cornell Medical and Memorial Sloan Kettering. Among his extramural duties, he is a member of the U.S. Food and Drug Administration Medical Imaging Drug Advisory Committee and a reviewer for the Damon Runyon Cancer Foundation Innovation award.

Dr. Hope: Let's start in the beginning. Why nuclear medicine?

Dr. Osborne: I had finished doing an $\mathrm{MD} / \mathrm{PhD}$ at Columbia. I realized in my third year of medical school that I was quite visual and so was looking for something that matched that realization. A lot of what we had done at the time in the lab in mice was looking at green fluorescent protein and other optical markers for neuron guidance. The combination of science and nuclear medicine seemed like the perfect fit.

Dr. Hope: What are you currently doing in nuclear medicine, and what do you find most exciting about some of the projects on which you're working?

COPYRIGHT @ 2020 by the Society of Nuclear Medicine and Molecular Imaging.
Dr. Osborne: I made the decision to go into radiology and nuclear medicine because there's a lot of flexibility with the application of science in the field of nuclear medicine. Also, there's a lot of patient interaction in nuclear medicine, and that was appealing. These days, I am interested in making sure radionuclides are readily available to academic and nonacademic sites. I get excited when one of our brilliant radiochemists puts together a really interesting compound to look at diseases like prostate

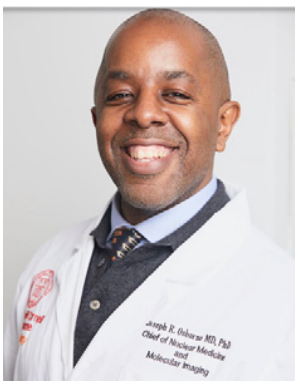

Joseph R. Osborne cancer. We're currently looking at many different prostate-specific membrane antigen (PSMA) compounds that are being developed. Finding patient populations that would benefit most from those compounds is equally exciting.

Dr. Hope: Going back to your beginnings, can you talk a little bit about mentorship early on and how that got you into nuclear medicine?

Dr. Osborne: I'd have to give a lot of credit to my $\mathrm{PhD}$ advisor, Richard Axel. One of the things that I loved about being in his lab was the approach that focused on asking the question rather than just doing the science. He won the Nobel Prize in 2004 for cloning the first set of olfactory receptors and pheromone receptors. While he was cognizant of the small details, he was more interested in the big questions: What's out there? What should be done next? When he heard what I wanted to do and where I wanted to do it, he started asking questions. At the time, he was on the board of scientific advisors at Sloan Kettering. He knew a lot of urologists and said, "You know, you've been here 5 years in the lab. You have all these big questions. So what are you going to do about it?"

The challenge has to be there. We can't be complacent in where we are or what we've done. It's about what you're going to do next. That's all that really matters. The person you mentor shouldn't aspire to be you-I don't want to mentor a clone of me. I want to mentor somebody who wants to do something different. It's about asking different questions and building on what's been done. It's about making an impact and looking at things through a different lens.

Dr. Hope: When you went to your first SNM annual meeting, what was that like? And what did you think of the first one you attended?

Dr. Osborne: I attended my first SNM meeting with Steven Larson. When I finished medical school, I decided to take a gap year to do a postdoc in molecular imaging over at Sloan Kettering with Steve and Ronald Blasberg, MD. As part of my fellow year, we went to the SNM in San Diego. It was a bit overwhelming. I 
had been to the Society for Neuroscience, so I had been to big meetings before but hadn't been to something where I felt like this is what I was going to do next. It felt like a community, and that inspired me. At the time, I wasn't sure how I was going to fit in or how I would make an impact in the SNM community. My greatest concern when I went to San Diego was that minority representation was quite low. The $\mathrm{PhD}$ and nuclear medicine communities are similar in that the percentage of underrepresented minorities is below that in the rest of the population. I speak with Steve regularly, so some things stay the same. I'm still talking to him about what I'm going to do next, and he's still there guiding me.

Dr. Hope: Let's change direction. You spoke about fitting in, and I think that's an important question right now. Can you comment a little bit on the differences related to being Black and being a minority? Is there a difference?

Dr. Osborne: I would say that the dividing line for me is a little bit different. What are the questions being asked, and what has been done in the recent past? Diversity, sex diversity, and racial diversity are very different things. You can have progress in one without having progress in another, because the issues are so different.

There are few underrepresented minorities in fields like radiology, radiation oncology, and nuclear medicine. Organizational societies have to be very intentional. If you want to be inclusive, then you have to go out and find the talent. You can't sit back and wait for the talent to come to you, or no one will come. I think nuclear medicine as a field about whether this is a place where they can feel included and have the opportunity to grow?

Dr. Osborne: New York City, since about 2014, has been a majority minority city. There are defined disparities in prostate cancer and prostate cancer deaths in the city and its boroughs. When I started, imaging was not the answer to bending the curve in prostate cancer but is now quite relevant. We have the opportunity to make a positive clinical impact and improve outcomes. In Brooklyn, we're seeing 2.5 times the mortality rate for prostate cancer. Can we bend that curve with PSMA? Absolutely! Especially as PSMA is about to be approved and we work to ensure access to trials for the patients who need them most in the New York City metropolitan area. We need our trainees to mirror the community, understand the gaps because they or people they know have experienced them, and ask questions that drive the science.

Dr. Hope: You bring up a very good point: there are huge disparities in the setting of trials and access to patients. Is there anything you thought about doing or have been able to enact to address any of these issues?

Dr. Osborne: We wrote a paper a few years back with Daniel Spratt, MD, looking at castrate-resistant prostate cancer, and this disparity was very clear. At the time, we were looking at genes and other factors that might be different between the populations. A couple of years later, in 2019, we reported in JAMA Oncology that if results from Black patients are pooled together in data from all castrate-resistant prostate cancer clinical trial populations, their

\section{"Change has to come from the majority.... If you want to be inclusive, then you have to go out and find the talent. You can't sit back and wait for the talent to come to you, or no one will come."}

medical specialties should aim to mirror the populations they serve. If that's not a primary goal, then it's only a matter of time before these societies fade away. It's the patients and understanding the varying population demographics and the disease burdens that impact those populations, especially in underserved areas, that will determine what happens next in health care.

Dr. Hope: One of the things that would be nice to think about are what types of granular changes that SNMMI as an organization could make to help break down barriers that prevent minority representation or to encourage people of color to join the field.

Dr. Osborne: What we're doing right now in this interview is incredibly important. If people don't believe that underrepresented minorities are already in the field and thriving, they just won't come. If these issues aren't being discussed, then no one will ever come. It's important from a leadership perspective to always have this be a part of the conversation.

We also have to look at leadership and take a deep dive at recruiting processes. We have to be very intentional about how we hire and how we think about who needs to come next and why. We have to push ourselves to do the opposite of what we've been doing for the past 20 years. For example, Steve Larson is not like me at all. We have similar interests, but we're very different. My current chair, Robert Min, MD, is not like me, but he recognized that "different" is what we needed at Weill Cornell.

Dr. Hope: In terms of increasing diversity, particularly in terms of underrepresented minorities, it is key to get people to go into medical school and then for those in medical school to choose this field. What would you tell Black trainees who are considering outcomes are very similar to those of individuals of European descent. This suggests that if you are able to get people into trials, a lot of this disparity may go away.

Even more so than genes, it's really about access to the trials. The question at Weill Cornell-and our focus-is how do we expand access to our clinical trials to more demographics, especially in underserved areas? If we do a clinical trial here for prostate cancer and $90 \%$ of participants are of European descent, then we haven't answered the question. We have to pool our resources as a system and find ways to provide access and enroll patients from areas like Queens and Brooklyn. We have to accrue as aggressively in Queens and Brooklyn as we do on the Upper East Side.

We also should be looking at clinical trial data carefully on a rolling basis, not just at the end of recruitment, making sure we have an acceptable balance. If you look at Black male representation in the prostate cancer database of the Cancer Genome Atlas, there are too few to make any conclusions - so you might as well have had zero. If you can't do genetic discovery, then why try at all? My priority here at Weill Cornell is ensuring that everybody is on a clinical trial who should be. The underlying goal is to get to the point where more people are being treated or imaged who need it.

Dr. Hope: One of the things that the Black Lives Matter movement really highlighted for me is the extent of how systems in place in our society reinforce disparities. I don't think many White people are aware of the history of systematic disparities and the ways in which they've played a role in medicine. Do you think you can take a minute to talk about how medicine has been influenced by this? 
Dr. Osborne: People don't like to think of New York City as being segregated, but it is. As I said earlier, it is a majority minority city, but only in certain communities. You'll find it to be $90 \%$ minority in Bedford-Stuyvesant in Brooklyn but only 5\% on the Upper East Side around Weill Cornell. When someone in Brooklyn needs medical assistance, they will go to Brooklyn Methodist if they have insurance and probably Kings County Hospital Center if they don't. If they're on the Upper East Side, they come to Weill Cornell. That alone drives a huge disparity, because if the hospitals that serve minority communities are suboptimal, then that's the kind of care someone there will get. These disparities are happening right now. It's not something that happened 30 years ago.

In 2002, I bought a brownstone in Harlem. At the time, Harlem was not quite gentrified, and no one would lend to me. The only large bank that considered me was Wells Fargo. A few community banks offered subprime loans. Although I had finished my $\mathrm{MD} / \mathrm{PhD}$, was about to start radiology residency, had plenty of money, and had perfect credit. Still, I could barely get a loan for a house in Harlem. Redlining - that is the story of those neighborhoods and the people of color trying to secure loans. The access to good health care isn't great, and neither are some of the neighborhoods. But part of the problem is that no one will lend money. The same thing happens for the hospitals. If hospitals have a bad payer mix, they may struggle to deliver the same kinds of services because they know it may impact the bottom line.

Dr. Hope: The field of nuclear medicine is very White. It's not your job as a Black leader at Weill Cornell to drive this change by yourself. It also has to be the responsibility of everyone. That's part of the point here: to make people aware of the issues so that it's not just the Black population in our field who are driving change.

Dr. Osborne: There are so many other things going on professionally and personally with Black physicians that asking them to bear the burden alone is not the answer. If you want to go around the hospital and ask which practitioners are most likely to have hypertension or diabetes, it's usually the Black physicians. That's where things like allyship become so important in driving change.

The most important thing that our field should know is that in order to drive change, that change must be both organic and intentional. Change has to come from the majority. I really believe that without intentional change, groups or medical societies will ultimately fail. I think we're onto some really brilliant things scientifically, but without an audience, without the patients, without resembling our society, it's just a matter of time. SNMMI has to be more inclusive in order to preserve itself.

Dr. Hope: Are there any anecdotes from your experience of how important it is to have the physician workforce mirror that of your patient population?

Dr. Osborne: Here at Weill Cornell, recruitment has been intentional, especially the hiring from the top, which has changed the appearance of the workforce, even at the resident level. New York-Presbyterian has hired its first Black chair in 250 years, and her vice chairs include Blacks as well as Latinas in the residency workforce. We are currently trying to mirror these changes in radiology with our incumbent vice chair in diversity equity and inclusion, Kemi Babagbemi, MD, and in my MI4 equity lab. I've talked to many of these individuals about their experiences with patients, which have changed dramatically, in part because patients now come here because they have that connection.

Whether at Sloan Kettering or here at Weill Cornell-great institutions with brand recognition-people will not come just because of who we are. There has to be trust and not only in the science. My father, who just passed away, was a dentist. He would never, ever have come to Sloan Kettering or Weill Cornell. He just wouldn't do it. He would feel that he could get his care somewhere else where he "knew" the people and where care was personalized to who he was as a patient and as a human being. That's the thing that people find the most surprising. They think because we're great and we've done a lot of wonderful things, that people will come; they are not correct.

Dr. Hope: To put that together, a diverse workforce increases inclusion, which then breaks down disparity in access-it's a great point. Thank you for taking the time to talk about these issues. They are a little bit difficult to talk about, but your perspective is incredibly valuable. Hopefully some people will learn about different approaches that we can take to help make things better.

Dr. Osborne: I really applaud you for coming to discuss things that aren't easy to discuss. Most often we talk about different things, such as trials and radionuclides. But sometimes we need to talk about these issues, too. They're important as well. And I'm always here. 